\title{
CARACTERIZAÇÃO MORFOLÓGICA DE GRÃOS EM LÂMINAS DELGADAS POR MEIO DE TÉCNICAS DE PROCESSAMENTO DE IMAGEM
}

\author{
GRAINS MORPHOLOGICAL CHARACTERIZATION IN SLIDES USING IMAGE PROCESSING \\ TECHNIQUES
}

\author{
Juliana da Mota COELHO ${ }^{1}$, Elisangela Lopes FARIA ${ }^{1}$, Lucas Valadares VIEIRA ${ }^{2}$, Maury \\ Duarte CORREIA ${ }^{2}$, Marcelo Portes ALBUQUERQUE ${ }^{1}$, Márcio Portes ALBUQUERQUE ${ }^{1}$, \\ Clecio Roque BOM ${ }^{3}$ \\ ${ }^{1}$ Centro Brasileiro de Pesquisas Físicas. R. Dr. Xavier Sigaud, 150 - Urca, Rio de Janeiro - RJ. \\ Emails: julianamtcoelho@gmail.com; elisangela@cbpf.br; marcelo@cbpf.br; mpa@cbpf.br \\ ${ }^{2}$ Cenpes - Centro de Pesquisas e Desenvolvimento Leopoldo Américo Miguez de Mello. Av. Horácio Macedo, 950 - Cidade \\ Universitária da Universidade Federal do Rio de Janeiro, Rio de Janeiro - RJ. \\ Emails: lucasvaladares@petrobras.com.br; mauryduarte@petrobras.com.br \\ ${ }^{3}$ Centro Federal de Educação Tecnológica Celso Suckow da Fonseca. Av. Maracanã, 229 - Maracanã, Rio de Janeiro - RJ. \\ Email: clecio@debom.com.br

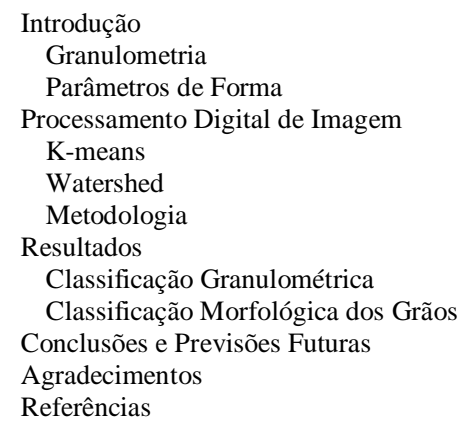

RESUMO - Métodos automatizados de análise de imagem de lâmina petrográfica têm tido destaque nos últimos anos com o avanço das técnicas de Processamento Digital de Imagens (PDI). A granulometria de uma rocha sedimentar clástica auxilia na compreensão dos processos pelos quais uma rocha passa durante sua deposição, além de poder estar relacionada a sua permo-porosidade. Entretanto, as técnicas amplamente utilizadas na análise granulométrica de rochas sedimentares são lentas e muitas das vezes bastantes subjetivas. Estas técnicas manuais são a observação microscópica direta e a medição do número de grãos por técnicas de peneiramento. Em contrapartida, as técnicas automatizadas de análise de imagem fornecem uma forma ágil de analisar o tamanho do grão e a forma das partículas sedimentares. Sendo assim, este trabalho teve como objetivo definir uma nova abordagem para medição de granulometria de maneira automática e definição dos parâmetros de forma dos grãos do Arenito Idaho.

Palavras chave: Processamento de imagem, Segmentação, K-means, Fator de forma, Arenito.

\begin{abstract}
Automatic methods focusing on image analysis of petrographic thin section have been developed in recent years with the advance of Digital Image Processing techniques (DIP). The granulometry of a clastic sedimentary rock, not only allows understanding of the different processes involved in the rock deposition, as also it is related to the permo-porosity of the rock. However, the techniques commonly used in granulometric analysis of sedimentary rocks are slow and often quite subjective. In general, these techniques are manual methods consisting of direct microscopic observations and measurements of the number of grains by using sieving techniques. In opposition, an automatized image analysis technique provides a rapid method to analyze the grain size and the morphology of the grains in sedimentary samples. Therefore, this work had as the main objective to define a new automatic method for measurements of granulometry and morphology of the grains in thin images. Finally, the method was applied on an Sandstone Idaho thin section.
\end{abstract}

Keywords: Image processing, Clustering, K-means, Shape factor, Sandstone.

\section{INTRODUÇÃO}

O uso das técnicas de PDI tem sido cada vez mais utilizado em estudos envolvendo a análise de imagens petrográficas. Muitos destes estudos estão relacionados à definição e análise do tamanho, forma e textura das partículas. Com o avanço das técnicas de PDI agregada a elevada resolução das câmeras acopladas aos microscópios óticos é possível uma análise mais rápida e detalhada do tamanho e forma da partícula (Schön, 2011), em comparação ao método de contagem de pontos em lâminas delgadas (Friedman, 1958). As técnicas de PDI apresentadas neste trabalho também fornecem uma alternativa ao método de peneiramento em 
casos de rochas consolidadas.

Do ponto de vista da geologia de petróleo, as rochas sedimentares clásticas formam uma grande proporção dos reservatórios de hidrocarbonetos. Destacam-se os arenitos, que formam os campos de turbiditos das bacias do sudeste brasileiro; e os grainstones, rochas carbonáticas que compõe parte dos reservatórios da província Pré-Sal.

Os grãos que compõe uma rocha sedimentar clástica são formados através do transporte hidrodinâmico de materiais formados dentro ou fora da bacia sedimentar. $\mathrm{O}$ estudo das características morfológicas destes grãos fornece indícios sobre a distância de transporte e o tipo de processo físico que os transportou e depositou (Reading, 1996).

Estes grãos podem ter tamanhos variando de menos de quatro micrometros (argilas) a mais de 256 milímetros (blocos), e ser compostos por minerais ou fragmentos de outras rochas. Os critérios básicos para a descrição dos grãos segundo (Altuhafi et al., 2013) são: tamanho e forma das partículas individualmente e a distribuição dos tamanhos das partículas ou granulometria. Muitos estudos envolvendo esta sofisticada análise quantitativa baseada em PDI vêm sendo proposto na literatura nos últimos 10 anos (Varga et al., 2018) (Altuhafi et al., 2013) e (Dipova, 2017). Em (Liu et al., 2015) os autores afirmam que estas novas abordagens relacionadas a quantificação de tamanho e parâmetros em areias tem relação com o avanço na capacidade de imageamento de partículas e da computação.

Dentro deste contexto e no intuito de apresentar uma nova abordagem acerca do estudo de partículas sedimentares, dois objetivos principais foram propostos neste trabalho: (1) o uso de PDI para definição e análise de medidas dos grãos (granulometria); (2) o uso de PDI para definição e análise de parâmetros morfológicos de partículas, mais especificamente grãos de areia e silte. Para ambos os objetivos foi utilizado uma imagem de lâmina delgada do arenito Idaho.

O presente trabalho foi desenvolvido no intuito de apresentar uma nova abordagem acerca do estudo de partículas sedimentares. Sendo assim, inicialmente é feita uma introdução sobre o problema abordado, onde são apresentados alguns conceitos fundamentais para o entendimento do trabalho proposto, assim como trabalhos correlatos. Em seguida, o processamento de imagens é abordado de uma maneira mais ampla, ou seja, quais são suas principais etapas, porém com ênfase nas técnicas que foram utilizadas neste trabalho. A metodologia para alcançar os objetivos propostos é apresentada a seguir e por fim são apresentados os resultados alcançados e as conclusões geradas a partir da metodologia proposta.

\section{Granulometria}

Os métodos tradicionais para granulometria fazem uso de procedimentos com elevado custo, como peneiramento, centrifugação e sedimentação. Estes métodos ainda perdem eficiência, ou são inviáveis, no caso de rochas muito consolidadas, por cimentação e/ou compacidade mecânica, casos nos quais os métodos para desagregação dos grãos podem modificar as características reais dos mesmos. Com o advento do poder de computação de alto desempenho, a disponibilidade de câmeras com melhor resolução e o avanço das técnicas de PDI, a granulometria baseada em imagem está se tornando viável. Algumas vantagens de se usar imagens e as técnicas de PDI sobre peneiramento tradicional são: (i) é um procedimento não destrutivo; (ii) é relativamente rápido permitindo a análise de muitas amostras e (iii) não se faz necessário a compra de novos equipamentos ou elaboração de novo aparato instrumental, uma vez que o microscópio ótico já é um equipamento presente nos laboratórios de sedimentologia.

A medição feita através do PDI traz uma nova perspectiva para a obtenção de uma máxima precisão das medidas petrográficas e consequentemente, as incertezas provenientes dos métodos manuais e tradicionais de medida também podem ser reduzidas. No trabalho proposto por (Dornaika \& Zhang, 2000), o objetivo dos autores foi a estimativa de granulometria em uma amostra de rocha sedimentar utilizando algumas técnicas de PDI. A cadeia de processamento de PDI utilizada foi dividida em três etapas: o ajuste de contraste da imagem; a segmentação através das técnicas de limiarização e a aplicação de operadores morfológicos de dilatação e erosão. Os autores também simularam computacionalmente o volume dos grãos estudados tendo como base duas imagens da mesma amostra visando uma relação com os métodos tradicionais, onde a granulometria é realizada em relação ao volume de cada classe de tamanho de sedimento 
encontrado na amostra. A ideia foi encontrar valores de granulometria muito semelhantes aos encontrados nos métodos tradicionais. O trabalho publicado por (Dipova, 2017) também realizou um estudo acerca da distribuição do tamanhos de grão de areia no solo utilizando PDI. Entretanto, as imagens utilizadas foram capturadas a partir de um setup experimental construído pelo próprio autor, onde foi utilizado uma câmera de 15 megapixels de resolução. Assim como no trabalho citado anteriormente, os autores também fizeram uso da técnica de limiarização na etapa de segmentação, porém foi acrescentada a técnica de watershed como pós processamento a esta etapa.

\section{Parâmetros de forma}

O segundo objetivo descrito no trabalho proposto envolveu a determinação dos parâmetros morfológicos. Paulatinamente os pesquisadores estão procurando métodos novos e automáticos para a determinação da forma de grão para depósitos arenosos (Schön, 2011). Em especial nos últimos 10 anos, os estudos automáticos da morfologia das partículas sedimentares vêm tomando grande relevância. Um trabalho visando a análise de tamanho e forma de grãos de areia utilizando métodos de PDI foi proposto por (Altuhafi et al., 2013). Neste trabalho foram comparados valores de convexidade, esfericidade e raio axial em 36 grãos de areia.

A análise do tamanho e forma foi realizada por meio de um aparelho denominado QICPIC, equipamento desenvolvido pela SymplaTec para análise dinâmica de imagens por meio de fonte de luz pulsada e um algoritmo computacional que pode analisar diversos grãos em um curto espaço de tempo.
Em Chatterjee (2013) também foram utilizados parâmetros de forma para obter a classificação automática de minerais em rocha sedimentar por meio de 14 fatores morfológicos dos minerais das rochas analisadas. Foram utilizadas neste trabalho 189 imagens capturadas por máquina fotográfica e as mesmas foram separadas em 6 grupos distintos respeitando as características morfológicas encontradas nos minerais. Neste trabalho as técnicas de PDI foram utilizadas para realizar o processo de segmentação, mais precisamente, foram utilizadas a técnicas de limiarização juntamente com a técnicas de watershed. Watershed é uma técnica de segmentação de imagens do campo da Morfologia Matemática baseada em crescimento de regiões, tendo como base as regiões de mínimos locais.

Em (Liu et al., 2015) foram quantificados 15 parâmetros de forma em partículas resultantes de vulcanismo. Os autores fizeram uso da técnica de limiarização e de operadores morfológicos de erosão e dilatação para analisar imagens de lâminas petrográficas adquiridas por meio de microscopia eletrônica.

Por fim, cabe ressaltar que a análise de imagens petrográficas auxiliadas por computador (como é o caso dos estudos citados anteriormente e da proposta deste trabalho) é um método com grande potencial para examinar as qualidades de reservatórios granulares de hidrocarbonetos e a capacidade de caracterizar rapidamente algumas das propriedades do reservatório, como por exemplo, a granulometria (que pode estar relacionada à permeabilidade), a macroporosidade (aquela detectável em lâminas delgadas) e os parâmetros relacionados à forma dos grãos.

\section{PROCESSAMENTO DIGITAL DE IMAGEM}

O PDI trata da manipulação de uma imagem por computador de modo que a entrada e a saída do processo são imagens ou características associadas a ela (Gonzalez, 2016).

O objetivo de se usar o PDI é melhorar o aspecto visual de certas feições estruturais da imagem de forma a extrair e fornecer informações relevantes para a interpretação da mesma e posterior análises ou processamentos. Atualmente o processamento de imagens é uma das principais áreas de pesquisa dentro da engenharia e ciências de computação e podendo ser utilizado em diversas áreas de aplicação como na medicina através de análise de imagens biomédicas, em automação industrial envolvendo o uso de sensores visuais em robôs, ou mesmo na indústria de óleo e gás, como é o caso deste trabalho.

Existem diversas formas e diferentes etapas que podem ser incorporadas à cadeia de processamento de sistemas de PDI, mas de forma simplificada estas etapas podem ser estruturadas em cinco passos principais: 1) aquisição; 2) préprocessamento, 3) segmentação, 4) extração de características e 5) reconhecimento de padrões. $\mathrm{Na}$ figura 1 apresentada a seguir pode ser visualizada a sequência de passos abordada. 


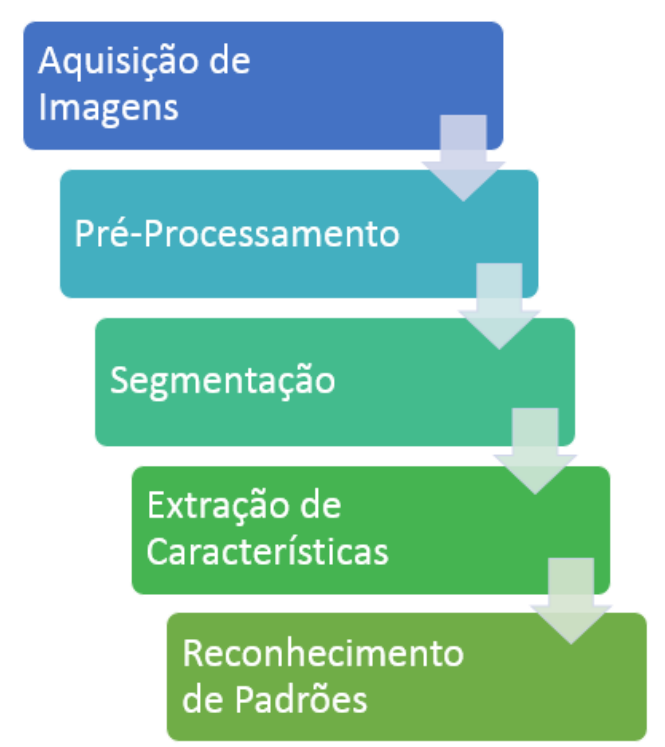

Figura 1. Esquema da cadeia de PDI simplificada.

O primeiro passo no processo de PDI é a aquisição apropriada de imagens que pode ser feita através de uma fonte, como por exemplo, um imageamento micro estrutural realizado através de um microscópio ótico e uma câmera digital. As imagens devem ser tomadas em um ambiente controlado e estável para evitar as influências de fatores externos. Mas na maioria das vezes, a imagem resultante do processo de aquisição apresenta diversas imperfeições que geralmente precisam ser corrigidas nas etapas posteriores, como a presença de pixels ruidosos, contraste e/ou brilho inadequado e outros artefatos indesejáveis.

$\mathrm{O}$ passo seguinte na cadeia de processamento, ou seja, o pré-processamento visa corrigir estes defeitos oriundos da aquisição melhorando assim a imagem e realçando detalhes importantes para a análise. Isto consequentemente facilita o processamento para as etapas subsequentes. Vários algoritmos podem ser utilizados nesta etapa como por exemplo, os filtros de passa baixa gaussiano, mediano e non local means que podem ser utilizados para remoção de ruídos na imagem ou mesmo os filtros edge, sobel e prewitt que visa detectar bordas na imagem, entre outros.

A segmentação é a etapa seguinte ao préprocessamento na cadeia de PDI. Ela visa subdividir a imagem em regiões ou objetos que a constituem, simplificando ou alterando a representação de uma imagem a fim de facilitar sua análise. Diversos métodos podem ser utilizados para esta finalidade, nos quais se destacam as técnicas baseadas no limiar, contorno da imagem ou regiões; métodos de agrupamentos de dados; métodos baseados em regiões e métodos de Redes Neurais Artificiais (Kaur \& Kaur, 2014). Para
(Belaid \& Mourou, 2009) esta etapa é recorrente em pesquisas que utilizam PDI estando presente em muitas aplicações de diferentes áreas de atuação.

Neste trabalho, na etapa de segmentação foram utilizados o algoritmo k-means que faz parte dos métodos de agrupamentos de dados e a técnicas de watershed que faz parte dos métodos baseados em regiões, ambos citados anteriormente. Sendo assim, apenas estes dois algoritmos serão detalhados no final desta seção. Entretanto mais informações sobre os demais métodos podem ser encontradas em (Gonzalez \& Woods, 1998).

Uma vez que a imagem já está segmentada, a mesma pode ser então utilizada na etapa de extração de características. Esta etapa visa, através de descritores da imagem encontrar alguma informação quantitativa essencial para a discriminação entre as classes de objetos. Estes descritores geralmente são utilizados para descrever propriedades diferentes na imagem, como cor, textura e forma de seus objetos e é importante que os mesmos em sua definição sejam invariantes as transformações geométricas como rotação, escala e translação. Para atender a proposta deste trabalho foram utilizados diferentes descritores de forma para análise de partículas obtidas a partir do processamento de uma imagem de lâmina delgada de arenito.

A última etapa na cadeia de PDI está relacionada ao reconhecimento de padrões que é o processo de atribuir um rótulo ou uma classe a um objeto. A ideia principal nesta etapa é transformar dados quantitativos, obtidos a partir dos descritores utilizados na etapa anterior, em outras informações relevantes sobre o objeto de estudo.

Por fim, cabe ressaltar que a sequência de PDI apresentada aqui não segue o padrão necessário para todas as aplicações, ou seja, não existe uma obrigação de todas as etapas serem realizadas, assim como também uma ou outra etapa pode ser repetida a fim de se obter uma melhoria nos resultados.

\section{K-Means}

$\mathrm{O}$ algoritmo K-means é um método de agrupamento de aprendizagem não supervisionada cujo o objetivo é identificar e determinar padrões e/ou regiões em uma base de dados, com um número de grupos definidos a priori, representados por uma variável (K).

Os padrões encontrados procuram determinar e identificar automaticamente como os dados estão organizados na base de dados (Duda et al., 2007). 
Apesar de sua simplicidade, o algoritmo k-means é muito popular em aplicações envolvendo agrupamento de dados e segmentação. $O$ seu funcionamento apresenta 4 passos básicos que são descritos a seguir:

Passo 1: Definir o número K de agrupamentos e escolher uma estimativa inicial para os centros dos agrupamentos c. Estas estimativas podem ser geradas de forma aleatória, selecionadas aleatoriamente a partir do conjunto de dados ou também podem ser geradas a partir de alguma heurística.

Passo 2: Cada ponto de dados (no caso de imagens cada ponto de dados é um pixel) é atribuído ao seu centroide mais próximo com base em uma métrica de distância. Mais formalmente, se $\mathrm{c}_{\mathrm{i}}$ for a coleção de centroides no conjunto $\mathrm{C}$, cada ponto de dados $\mathrm{x}$ será atribuído a um agrupamento com base na seguinte equação:

$$
\underset{c_{i} \in C}{\operatorname{argmin}} \operatorname{dist}\left(c_{i}, x\right)^{2}
$$

Onde dist(.) é geralmente a distância euclidiana.

Passo 3: Atualização do centroide: os centroides são recalculados tomando a média de todos os pontos atribuídos ao agrupamento deste centroide. Ou seja, para cada dado $S_{i}$ atribuído ao i-ésimo centroide, esta atualização pode ser realizada por:

$$
c_{i}=\frac{1}{\left|S_{i}\right|} \sum_{x_{i} \in S_{i}} x_{i}
$$

Passo 4: Repetir passo 2 e 3 para todos os dados (ou pixels da imagem) até que um critério de parada seja alcançado. Geralmente este critério de parada está relacionado ao número máximo de iterações ou quando não há nenhuma mudança nos valores dos centroides.

A imagem resultante após a segmentação com $\mathrm{K}$-means é uma imagem onde todas as k regiões presentes foram separadas possibilitando assim, para o caso onde $\mathrm{k}$ é igual a 2 , a definição do que é um objeto e outro.

Entretanto, para aplicações onde se faz necessário uma melhor divisão dos objetos, como é o caso deste trabalho (onde é importante a definição de cada grão individualmente) é importante a utilização do algoritmo de watershed (detalhado na próxima seção) para esta separação.

\section{Watershed}

A transformação de Watershed é uma das mais antigas técnicas de segmentação proposta por Beuche \& Lantuéj, 1973. Conforme citado anteriormente a mesma pode ser considerada como um classificador baseado nas regiões de contorno. A ideia intuitiva subjacente a este método vem da geografia (Serra, 1983) e a mesma é baseada na noção de divisão de águas de uma superfície, tal como um terreno, onde o objetivo é identificar as bacias de captação dos mínimos regionais.

A localização destas linhas d'água pode ser dada intuitivamente elevando um nível d'água uniformemente na superfície e traçando as linhas nos pontos onde águas provenientes de dois mínimos regionais diferentes se tocam, determinando assim um ponto de watershed.

Uma simulação deste procedimento intuitivo está representado na figura 2 onde pode ser visualizado uma superfície e também um nível d'água que eleva-se, identificando os mínimos regionais através de cores diferentes e traçando linhas onde as águas se encontram (Körbes, 2010).

Uma das características da transformada watershed é sempre fornecer contorno fechado para as estruturas segmentadas, esse é um fato relevante neste trabalho, pois os grãos analisados neste estudo são estruturas fechadas e com isso o algoritmo pode ajudar na quantificação desse material.

Outra vantagem a ser destacada é que o algoritmo requer um baixo custo computacional em comparação a outros métodos de segmentação (Belaid \& Mourou, 2009).

\section{Metodologia}

Conforme citado anteriormente, este trabalho visou a aplicação das técnicas de PDI envolvendo dois objetivos diferentes: (1) definição e análise de medidas de grãos (granulometria) e (2) definição e análise de parâmetros morfológicos de partículas, mais especificamente os grãos de tamanho areia.

A metodologia proposta para alcançar os objetivos neste trabalho é composta de 4 etapas fundamentais: (i) aquisição da imagem; (ii) préprocessamento; (iii) segmentação e (iv) pósprocessamento. Na figura 3 pode ser visualizado o workflow da metodologia proposta.

A imagem utilizada no processamento é a imagem de uma lâmina delgada do arenito Idaho cedida pelo Centro de Pesquisas e Desenvolvimento Leopoldo Américo Miguez de Mello (CENPES). Todo o processo de preparo da lâmina delgada e aquisição da imagem ficaram a cargo do mesmo. Na figura 4 podem ser visualizadas a imagem analisada (com dimensão de 
3013 x 4055 pixels) e um corte da mesma com dimensão de 548 x 800 pixels.

Este corte foi feito visando uma maior facilidade na visualização dos resultados de cada etapa da cadeia de PDI executada neste trabalho. Entretanto, cabe destacar que todos os resultados apresentados na seção 4 estão relacionados ao processamento da imagem original.

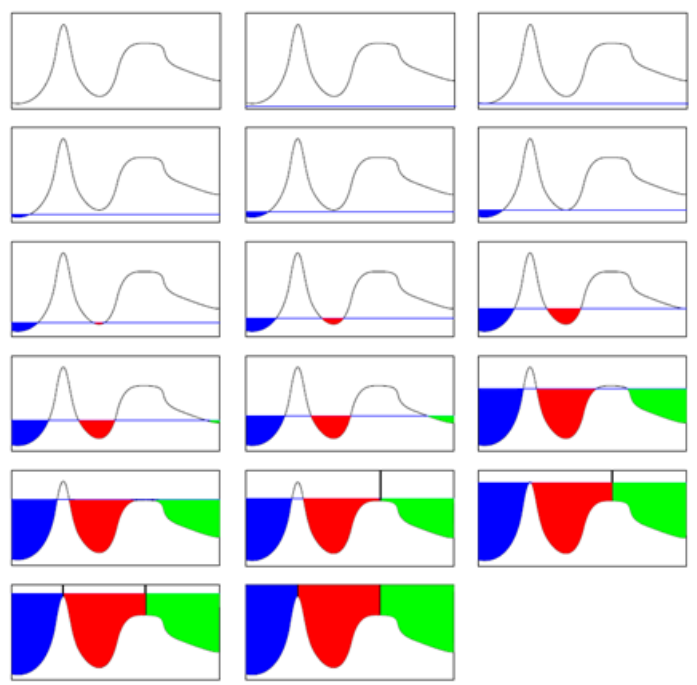

Figura 2. Exemplo da intuição da simulação de inundação no perfil de uma superfície (Körbes, 2010).

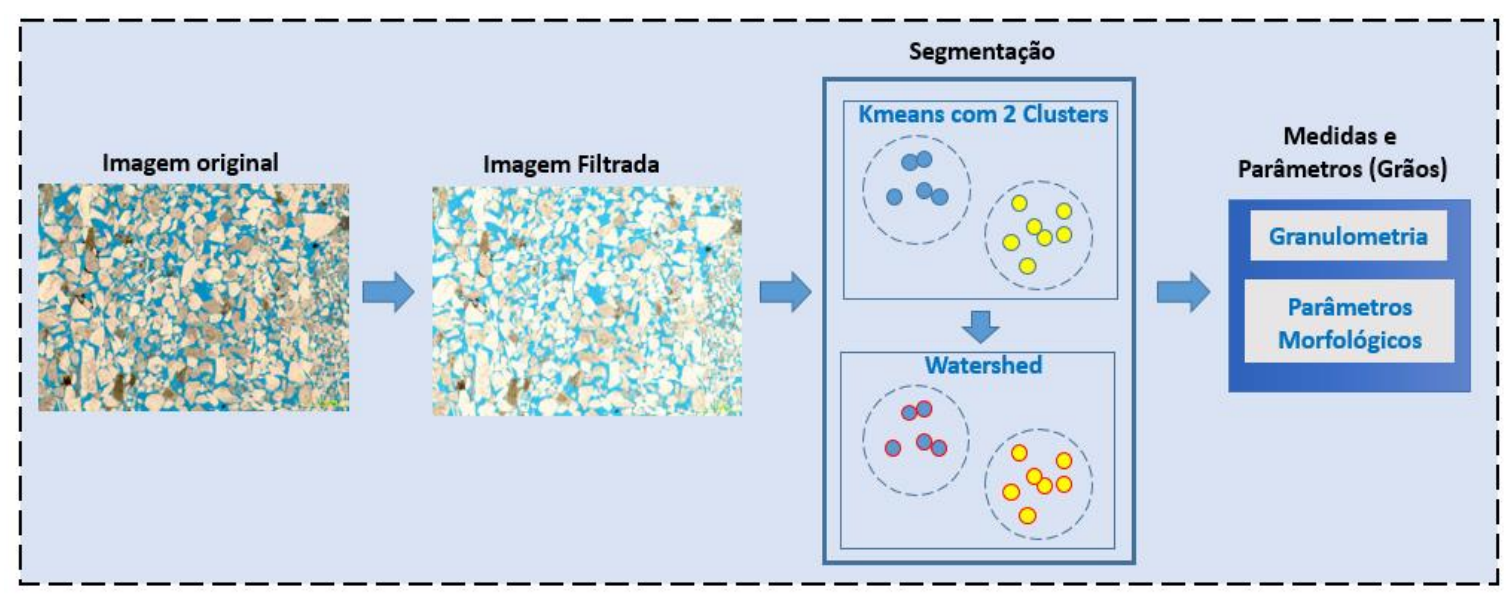

Figura 3. Metodologia aplicada no trabalho.

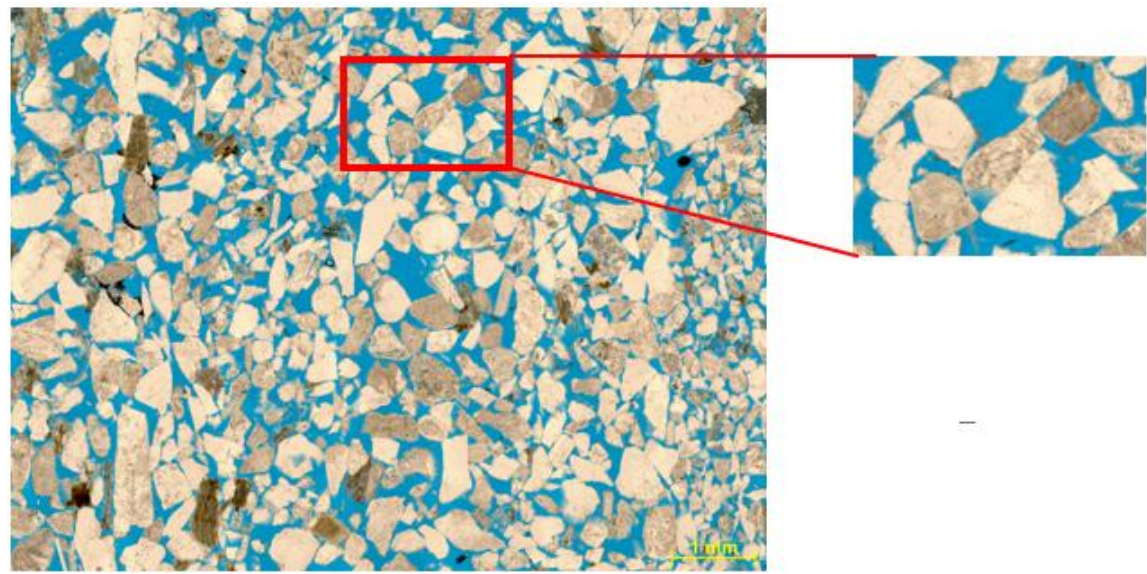

Figura 4. Imagem original e corte da lâmina de Arenito Idaho

Após a aquisição da imagem, a etapa de préprocessamento foi aplicada na lâmina. Como já discutido na seção anterior esta etapa visa remover ruídos indesejados e outros artefatos produzidos nas imagens durante a aquisição. Vários algoritmos de filtragem estão disponíveis para esta finalidade, dentre os quais 3 foram utilizados neste trabalho: filtros medianos, gaussiano e non local means. O filtro mediano permite uma atenuação dos ruídos mantendo os detalhes principais da imagem e o mesmo pode ser relevante para remover pixels isolados. Trata-se de um filtro não linear que 
classifica os pixels em uma região e substitui seu pixel central pelo valor mediano. Já o filtro gaussiano atenua as componentes da imagem de alta frequência (considerando-se o domínio de Fourier) mantendo inalterados os componentes de baixa frequência. Componentes de alta frequência ocorrem quando se tem uma variação espacial brusca dos níveis de cinza como é o caso de ruídos e contornos entre fases distintas da imagem. O efeito da aplicação deste tipo de filtro é o de suavização (uniformização) dos níveis de cinza da imagem. Por fim, o terceiro e último filtro testado foi o non local means (Buades, 2005) amplamente utilizado na remoção de ruídos em imagens. O mesmo, parte do princípio de que existem padrões que se repetem por toda a imagem tanto localmente quanto globalmente e tendo em vista esta informação, o algoritmo filtra cada pixel da imagem utilizando a informação contida nos demais, atribuindo pesos de acordo com o grau de semelhança entre eles.

A ideia principal na utilização dos filtros citados anteriormente foi verificar qual a influência destes filtros de diferentes características nos resultados obtidos no pré-processamento, além de melhorar a qualidade da imagem para as etapas posteriores.

A terceira etapa da metodologia proposta está relacionada com a segmentação da imagem que visa isolar cada grão para análise posterior. Processos de cimentação, dissolução e compacidade do grão deformam as bordas dos mesmos dificultando assim o processo de segmentação. Sendo assim, esta etapa foi realizada utilizando a combinação de dois métodos diferentes: um envolvendo o algoritmo k-means, onde foi possível definir o fundo e os objetos da imagem e outro envolvendo o algoritmo de watershed, onde foi possível identificar cada grão individualmente. A abordagem adotada visou facilitar a identificação dos grãos e também reduzir um fenômeno muito conhecido em aplicações envolvendo as técnicas de watershed denominado de oversegmentation (Gies \& Bernard, 2004).

Para o algoritmo K-means foi necessário a determinação da quantidade de agrupamentos a priori. Analisando a figura 4 que representa a imagem original é possível observar duas estruturas bem delineadas na imagem: os grão de arenito e os poros. Neste sentido o número de agrupamentos utilizados neste trabalho foram 2 , ou seja, duas fases distintas foram definidas na imagem. Outros parâmetros também definidos no algoritmo k-means foram: o número de iterações
(100); métrica de distância (euclidiana); número de vezes que o algoritmo foi replicado (10) e processo de inicialização dos centroides inicias (Arthur \& Vassilvitskii, 2007).

Em relação ao watershed foi utilizado o algoritmo proposto por (Meyer, 1991) implementado na versão 5.4 (R2007a) do software Matlab (Mathworks, 2017). A fim de melhorar os resultados obtidos pelo algoritmo, foi utilizada a transformada H-Mínima (Soille, 1999) antes da execução do mesmo. Esta transformada tem como objetivo suprimir os mínimos locais (considerados como regiões com intensidade de cor constante e que possuem uma fronteira externa com todos os pixels com uma maior intensidade) com profundidade maior que um parâmetro $\mathrm{H}$ pré estabelecido. Diferentes valores para o este parâmetro foram testados, sendo o valor que melhor separou os grãos definido como 5 .

$\mathrm{Na}$ figura 5 pode ser visualizado o resultado das etapas (i,ii e iii) da metodologia proposta e uma comparação entre os diferentes filtros utilizados na etapa de pré-processamento.

As imagens a, b e c estão relacionadas aos filtros gaussiano, mediano e non local means respectivamente. Em I pode ser visualizado a imagem original filtrada através dos três filtros analisados; em II tem-se o resultado da segmentação através do método K-means para as imagens filtradas; em III tem-se o resultado da segmentação por watershed e finalmente em IV é possível visualizar a imagem original e a definição de cada grão separado individualmente através das linhas de contorno obtidos pela watershed.

Analisando a imagem é possível concluir que a etapa de pré-processamento tem uma grande influência nos resultados. Os filtros (a, I), (b, I) e (c, I) que correspondem aos filtros gaussiano, mediano e non local means respectivamente apresentaram resultados semelhantes. Entretanto, em (a, I) e (b, I) é possível verificar que os filtros eliminaram os grãos pequenos e suavizaram demais as bordas dos grãos processados, diferenciando-os da forma original.

O filtro (c, I) foi o único que conseguiu separar bem todos os grãos presentes na lâmina preservando grande parte da forma do grão. Esta preservação da forma é importante pois como o trabalho visa o estudo dos parâmetros de forma do grão, a atenuação da borda pode ser prejudicial. Desta forma, todos os resultados obtidos na etapa posterior estão relacionados aos grãos obtidos a partir da seguinte configuração: (1) imagem 
original filtrada por non local means, (2) imagem segmentada por k-means e (3) imagem processada por watershed.

Conforme citado anteriormente, o objetivo deste trabalho foi a classificação granulométrica dos grãos presente na lâmina e quantificação dos parâmetros de forma dos grãos areia também presentes na mesma imagem (figura 4) utilizando técnicas de PDI. A capacidade de medir dimensões em partículas por meio do PDI permite a medida de diversas propriedades morfológicas da partícula, algumas complexas como por exemplo, o maior e menor eixo da elipse que se ajusta à imagem do grão.

Dentro deste contexto, a última etapa está relacionada a quantificação de parâmetros estruturais dos grãos, mais precisamente extração de informações quantitativas nas imagens resultantes da etapa de segmentação, ou seja, imagens binárias dos grãos. a
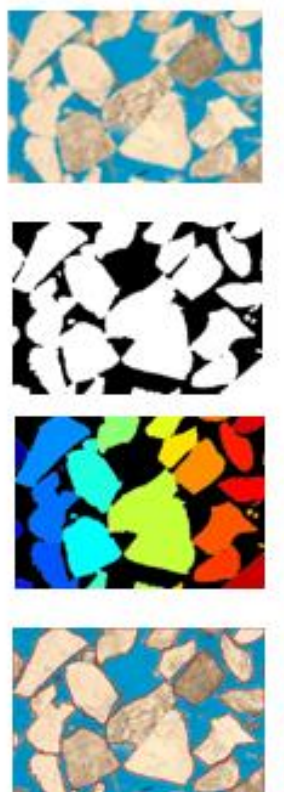

b
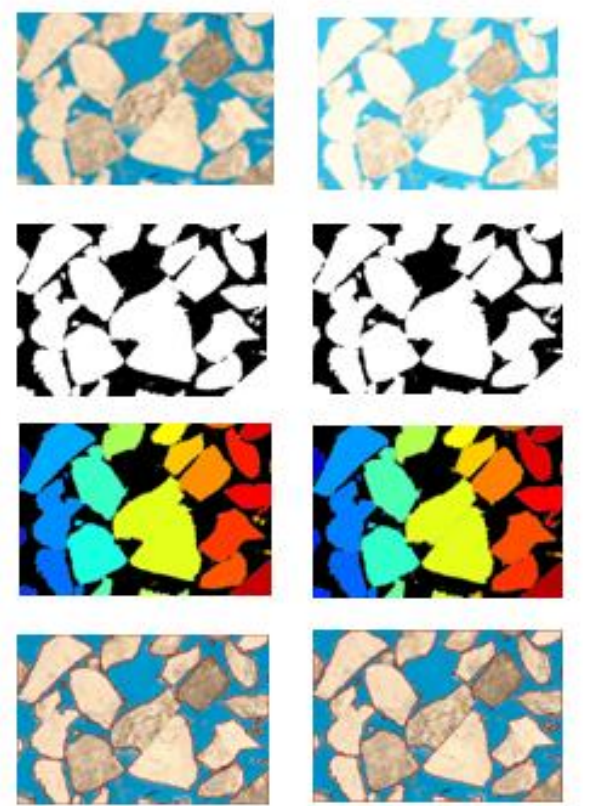

I
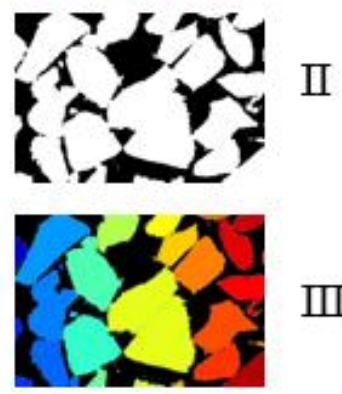

III

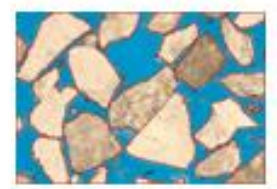

IV

Figura 5. Comparação dos filtros utilizados na etapa de pré-processamento, a) gaussiano b) mediano e c) non local means, em relação aos resultados obtidos ao final do processo de segmentação. I) Imagem original após a etapa de pré-processamento, II) Resultado da segmentação por K-means, III) Resultado do watershed e IV) Imagem original com limites dos grãos definidos.

Sendo assim, tendo como base a imagem do grão binário em duas dimensões, resultante da configuração citada anteriormente foram definidas as seguintes informações dos grãos: área, área do grão por convex hull, perímetro, perímetro por convex hull, eixo maior e menor da elipse que melhor se ajusta ao grão, além do diâmetro máximo de Feret. Por definição, o Convex Hull define o menor polígono que engloba os objetos da imagem selecionada, no caso do trabalho em questão o grão. A figura 6 a esquerda demonstra como pode ser delimitado este polígono.

$\mathrm{Na}$ tabela 1, podem ser visualizados todas as medidas calculadas.

Tabela 1. Sumário dos fatores do grão.

\begin{tabular}{|c|c|}
\hline Simbolo & Definição \\
\hline $\mathrm{A}_{\mathrm{p}}$ & Área do grão \\
$\mathrm{A}_{\mathrm{ch}}$ & Área do convex hull \\
$\mathrm{P}_{\mathrm{p}}$ & Perimetro do grão \\
$\mathrm{P}_{\mathrm{ch}}$ & Perimetro do convex hull \\
$\mathrm{D}_{\mathrm{maxferet}}$ & Diâmetro máximo de feret \\
$\mathrm{A}$ & Eixo maior da elipse de melhor ajuste \\
$\mathrm{B}$ & Eixo menor da elipse de melhor ajuste \\
$\mathrm{l}$ & Eixo maior do retangulo de melhor ajuste \\
$\mathrm{w}$ & Eixo menor do retangulo de melhor ajuste \\
\hline
\end{tabular}




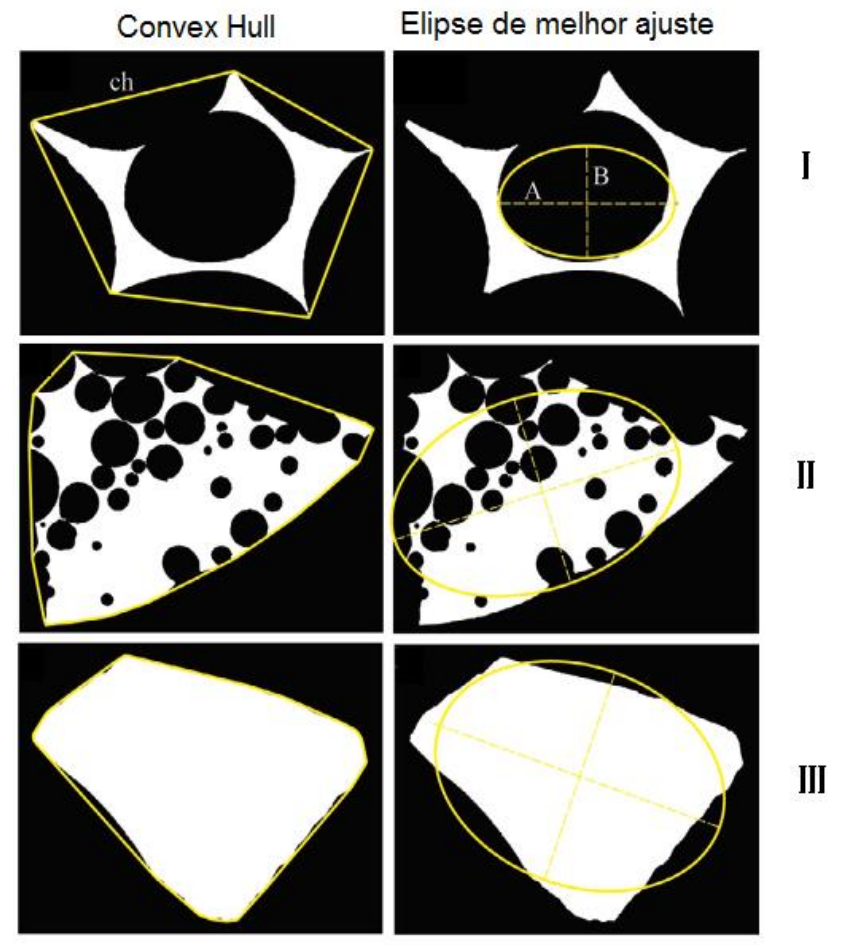

Figura 6. Influência da forma da partícula (I,II e III), no cálculo de convex hull e da elipse de melhor ajuste (Liu et al., 2015).

$\mathrm{O}$ parâmetro $\mathrm{A}_{\mathrm{p}}$ se refere a área do grão, ou seja, a soma dos pixels do objeto. $O$ segundo parâmetro da tabela, $\mathrm{A}_{\mathrm{ch}}$ está relacionado ao Convex Hull.

A determinação dessa geometria é importante quando se deseja determinar a área mínima onde estão inseridos determinados elementos em sua região de estudo. O fator A citado na tabela I está relacionado ao eixo de maior comprimento (em pixels) da elipse, que melhor se ajusta ao objeto, enquanto $\mathrm{o}$ fator $\mathrm{B}$, descreve $\mathrm{o}$ menor comprimento. Ambos retornados em valores escalares e conforme pode ser visualizado a direita da figura 6 é possível verificar como este valor se modifica dependendo da estrutura analisada. O fator 1 descreve o eixo maior do retângulo de melhor ajuste, ja o fator $w$ é o eixo menor do retângulo de melhor ajuste. No cálculo do perímetro $\mathrm{P}_{\mathrm{p}}$ é levado em consideração a distância entre cada par adjacente de pixels ao redor da borda da região do grão e $\mathrm{P}_{c h}$ é o perímetro do polígono criado pela operação Convex Hull.

Diâmetros de Feret são as distâncias entre duas retas paralelas tangentes aos lados opostos da partícula. A medida mais usada para medição de tamanho de grãos em imagens microscópicas está relacionada com o diâmetro máximo de Feret do grão (Karakus et al., 2010).

A partir dos fatores dos grãos identificados na tabela 1 foram analisados também 6 outros parâmetros que são muito importantes para a análise de grãos de rochas: circularidade, solidez, convexidade, compacidade, alongamento e angulosidade. Estes 6 parâmetros de forma foram calculados e quantificados usando formulações matemáticas discutidas por diversos autores (Liu et al., 2015), (Henstschel \& Neil, 2003) e (Varga et al. 2018) e também tendo como base os termos da tabela 1 citada anteriormente. A expressão para o cálculo destes parâmetros pode ser visualizada na tabela 2.

Tabela 2. Sumário dos parâmetros de forma adaptado.

\begin{tabular}{|c|c|c|c|}
\hline Simbolo & Abreviação & Formulação & Sensibilidade \\
\hline Circularidade & $\mathrm{CC}$ & $C C=\frac{4 \pi A p}{P p^{2}}$ & Forma e irregularidade \\
\hline Solidez & $\mathrm{SLD}$ & $\mathrm{SLD}=\frac{A p}{A c h}$ & Irregularidade morfológica \\
\hline Convexidade & $\mathrm{CVX}$ & $\mathrm{CVX}=\frac{P C h}{P p}$ & Irregularidade textural \\
\hline Compacidade & $\mathrm{CP}$ & $\mathrm{CP}=\frac{A \mathrm{p}}{l w}$ & Irregularidade morfológica \\
\hline Raio Axial & $\mathrm{AxIR}$ & $\mathrm{AxIR}=\frac{B}{A}$ & Forma \\
\hline Angulosidade & $\mathrm{RD}$ & $R D=\frac{4 A p}{\pi D_{\operatorname{maxferet}}{ }^{2}}$ & Forma \\
\hline
\end{tabular}




\section{RESULTADOS}

O trabalho foi realizado em duas etapas. A primeira etapa está relacionada a classificação granulométrica de todos os grãos presentes na lâmina. Enquanto na segunda etapa são apresentados os resultados da caracterização morfológica que foi realizada utilizando os grãos de areia classificados e selecionados na etapa anterior.

\section{Classificação Granulométrica}

A classificação granulométrica dos tipos de grãos foi realizada pelo modelo de classificação de partícula proposto por (Wentworth, 1922). O autor propôs uma grade de subdivisão dos tipos de sedimentos em uma rocha baseado no valor de phi obtido através da equação proposta por (Schön, 2011), onde é apresentada a seguir.

$$
P h i=-\log _{2} D_{\text {maxferet }}
$$

Na figura 7 pode ser visualizado o resultado da classificação obtida para os grãos encontrados na lâmina utilizada neste trabalho.

No método tradicional da estimativa de granulometria em sedimentos existe uma relação com o volume do grão, no entanto a análise proposta aqui se baseia apenas no PDI de uma imagem. Sendo assim, para uma aproximação melhor dos resultados alcançados em relação as técnicas tradicionais, o percentual foi calculado em relação a área total de cada classe de tamanho (por exemplo, areia média 33.7\%). Vale ressaltar que a soma da área dos grãos de areia na imagem totalizou $99 \%$ e tal resultado está de acordo com o valor esperado, pois a lâmina delgada estudada é de uma amostra de arenito.

A partir da classificação obtida utilizando o método (Wentworth, 1922) foi possível utilizar o diagrama proposto por (Folk, 1954) para a classificação de sedimento finos (areia, silte e argila).

Este diagrama triangular classifica as rochas de acordo com a proporção relativa dos tamanhos granulométricos medidos. Através dos resultados obtidos anteriormente os grãos classificados com a maior ocorrência na lâmina de Idaho são os de tamanho areia, com 99\% da área total de grãos. Logo, a rocha analisada pode ser classificada como um arenito (A), conforme visualizado na figura 8.

Outra medida interessante a ser relacionada é o grau de seleção do grão tendo como base a distribuição acumulada do percentual de área em relação a phi (gráfico apresentado na figura 7 a direita). Existem algumas fórmulas para calcular parâmetros estatísticos de tamanho de grão por métodos gráficos, dentre as quais é possível destacar o desvio padrão do gráfico inclusivo $(\sigma)$ (Boggs Jr., 2009) que foi a abordagem utilizado neste trabalho. A equação do mesmo é apresentada a seguir e foi proposta por (Folk, 1980).

$$
\sigma=\frac{84 \phi-16 \phi}{4}+\frac{95 \phi-5 \phi}{6.6}
$$

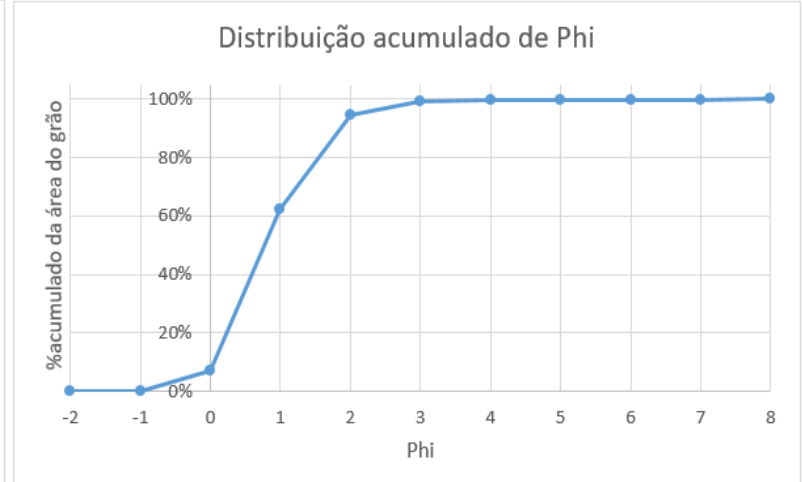

Figura 7 - Distribuição do intervalo de phi (esquerda) e distribuição acumulada do percentual de phi (direita).

Para cada intervalo de valores de $\sigma$ existe um grau de seleção para os grãos presentes em uma determinada amostra segundo (Folk, 1974), tais valores podem ser visualizados na tabela 3 .

$O$ valor de $\sigma$ encontrado na imagem analisada neste trabalho foi 0.92 o que caracteriza a rocha como moderadamente selecionada. Entretanto, Ishutov et al. (2015) descrevem os grãos como angulares a sub-angulares, possivelmente esta diferença se dá devido ao trabalho de referência ter utilizado o método de comparação visual (Powers, 1953). 


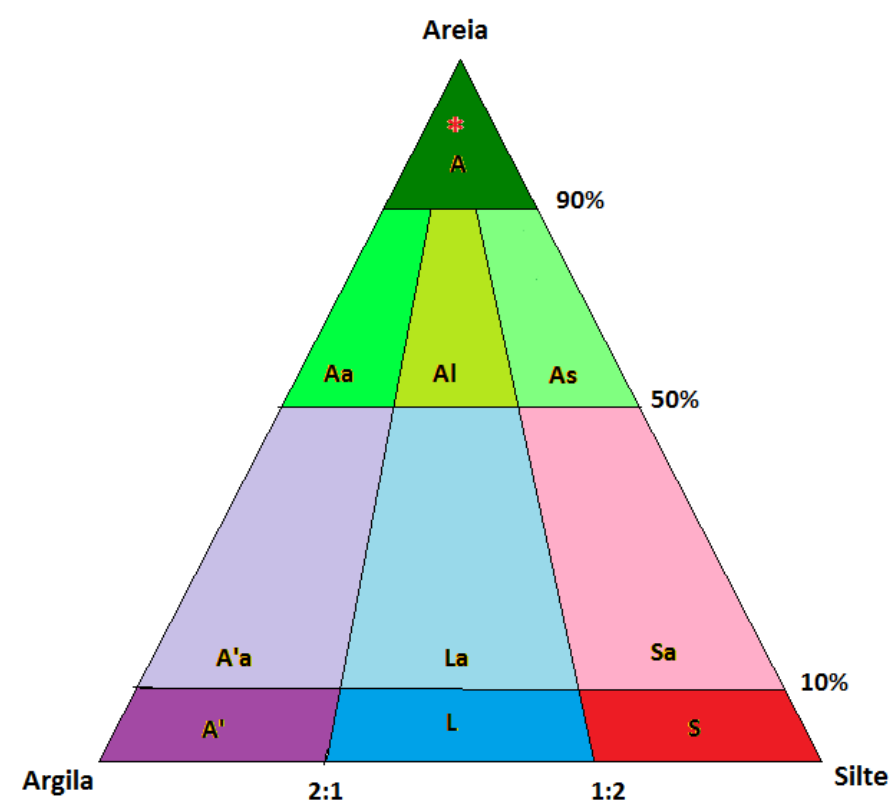

Figura 8 - Diagrama triangular de (Folk, 1954) adaptado de (Dias, 2004) para classificação de rochas finas. Os 10 termos no diagrama são A - arenito, Aa - arenito argiloso, Al - arenito lamoso, As - arenito siltoso, A' - argilito arenoso, La Lamito arenoso, Sa - siltito arenoso, A' - argilito, L - Lamito e S - siltito. A lâmina delgada da amostra analisada do arenito Idaho (representada pelo símbolo *) pode então ser classificada como um arenito siltoso.

Tabela 3. Subdivisão do grão de seleção do grão.

\begin{tabular}{cc}
\hline Grau de seleção & $\sigma$ \\
\hline Muito bem selecionado & $\leq 0.35$ \\
Bem selecionado & $0.35-0.50$ \\
Moderadamente bem selecionado & $0.50-0.70$ \\
Moderadamente selecionado & $0.70-1.00$ \\
Pouco selecionado & $1.00-2.00$ \\
Muito pouco selecionado & $2.00-4.00$ \\
Extremamente pouco selecionado & $\geq 4.00$ \\
\hline
\end{tabular}

\section{Caracterização Morfológica dos Grãos}

Os resultados da caracterização morfológica dos grãos discutidas nesta seção estão relacionados aos grãos classificados no tópico anterior com tamanho areia e está de acordo com as referências utilizadas neste trabalho. A caracterização morfológica destes grãos foi realizada através da medida de 6 parâmetros de forma: circularidade, solidez, convexidade, compacidade, raio axial e angulosidade. A função para o cálculo desses parâmetros pode ser visualizada na tabela II e tem como base as medidas dos fatores do grão exemplificados na tabela I.

Na figura 9 podem ser visualizados todos os parâmetros de forma e seus respectivos percentuais da área de cada classe de areias analisadas.

O primeiro parâmetro apresentado na figura é a circularidade. A análise da circularidade do grão (CC) é realizada comparando o grão analisado a um círculo, onde o círculo perfeito possui $\mathrm{CC}=1 \mathrm{e}$ formas mais complexas terão $\mathrm{CC}$ tendendo para 0. Através da figura é possível verificar que a maioria dos grãos descritos na lâmina delgada analisada apresentam valores de CC entre 0.6 e 0.7 e nenhum grão apresenta circularidade no intervalo de 0.9 a 1 . Sendo assim é possível concluir que os grãos não se assemelham a um círculo perfeito.

Os próximos parâmetros estudados foram solidez e convexidade e os mesmos são determinados tendo como base as medidas de convex hull. Ambos os parâmetros descrevem a dimensão em que uma forma é convexa ou côncava. Esse cálculo é realizado tendo como base a área para a solidez e o perímetro para a convexidade (Varga et al., 2018). O valor 1 tanto para solidez quanto para convexidade está relacionado a um objeto completamente 
convexo. Analisando a figura 9 é possível verificar que a maior quantidade de valores para ambos os parâmetros se concentram no intervalo de 0.8 a 0.9 , o que demonstra que os grãos não apresentam forma completamente convexa.
Outro parâmetro analisado foi a compacidade que foi calculada a partir da área do grão e dos eixos do retângulo que melhor se ajusta a sua forma, conforme citado na tabela 2 e proposto por (Liu et al., 2015).

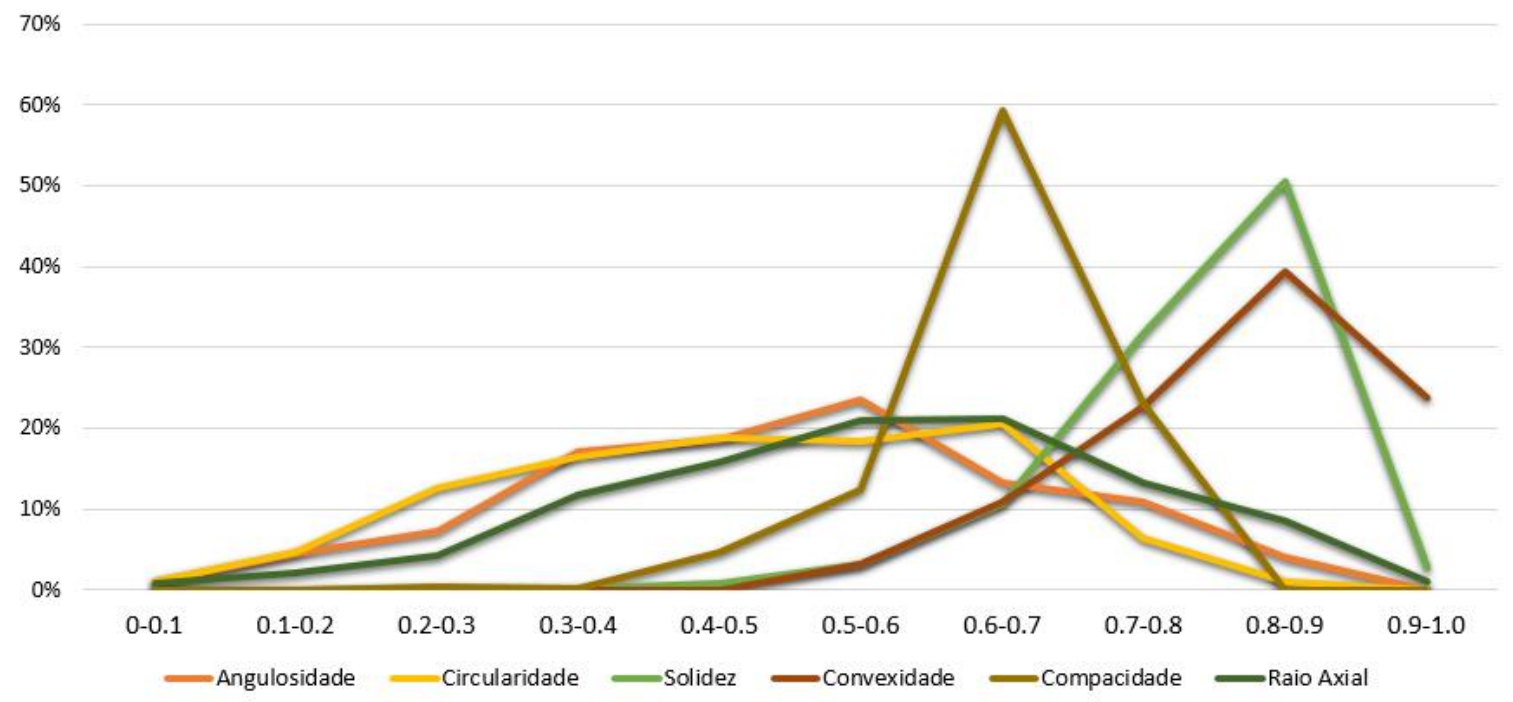

Figura 9. Proporção de valores encontrados de cada fator de forma.

Na figura 9 é possível verificar que não existem grãos com valores em todos os intervalos para o parâmetro analisado, ou seja, só existem valores no intervalo de 0.4 e 0.8 e $82 \%$ dos grãos estão no intervalo entre 0.6 e 0.8 . Isto se deve ao fato de que todas os grãos estudados pertencem a uma mesma lâmina delgada, logo apresenta a mesma formação geológica, ou seja, como a lâmina passou por processos de compacidades semelhantes, os seus valores para este parâmetro são próximos.

Através da figura 9 é possível verificar também uma diferença entre a compacidade e os demais fatores de forma. A linha de compacidade é completamente diferente das demais com o pico no intervalo de 0.6 a 0.7 , onde $59 \%$ dos grãos estão concentrados neste intervalo. $\mathrm{Na}$ amostra analisada não foram encontrados valores baixos de compacidade. Segundo interpretação proposta por (Dellino \& La Volpe, 1996) essa informação indica que não existem grãos com forma e contorno muito irregulares. Tal afirmativa pode ser comprovada observando o gráfico da figura 9 , onde $o$ percentual da compacidade são praticamente nulos para valores abaixo do intervalo 0.3 a 0.4 .

O Raio Axial é um dos parâmetros mais importantes dentre os parâmetros de forma estudado neste trabalho. O mesmo foi proposto por (Zingg, 1935) para diferenciar partículas com formato de disco e circulares. O cálculo do raio axial envolve a razão entre o maior e menor eixo da elipse que contém a partícula estudada. Pode se dizer que uma forma simétrica em todos os eixos apresenta o raio axial igual a 1. Analisando a figura 9 é possível verificar que os raios axiais apresentam valores semelhantes aos valores dos parâmetros de circularidade e angulosidade.

O último parâmetro discutido foi a angulosidade, que também pode ser conhecida como arredondamento e está relacionado a quão suave é a borda da partícula ou grão. A angulosidade se assemelha bastante à circularidade, pois as duas apresentam a sua sensibilidade relacionada com a forma do grão e traz informações sobre o retrabalhamento sofrido respondendo a questões sedimentológicas do grão (Cox et al., 2018). A semelhança entre os 2 parâmetros fica evidente ao se analisar o gráfico da figura 9, onde é possível verificar que a linha referente a angulosidade e circularidade estão próximas e em alguns pontos chegam a se sobrepor.

Analisando também a figura 9 é possível verificar que o maior percentual de grãos em um intervalo se encontra com valores próximos, ou seja, para a angulosidade $24 \%$ dos grãos estão entre 0.5 e 0.6 e para a circularidade $21 \%$ dos grãos estão entre 0.6 e 0.7 .

Visando uma análise mais completa acerca da angulosidade foi utilizada também a 
metodologia do gráfico de comparação visual de arredondamento proposto por (Powers, 1953) e com modificações para aplicação de PDI. Apesar do gráfico oferecer uma maneira rápida e fácil de estimar a forma de partícula bidimensional, as comparações das mesmas podem ser subjetivas. O uso de PDI é importante pois faz com que a classificação proposta por (Powers, 1953) seja menos subjetiva, aplicando valores de arredondamento para cada classe por ele nomeada, como pode ser visualizado na tabela 4 .

Tabela 4 - Classificação de arredondamento (Powers, 1953).

\begin{tabular}{cc}
\hline Muito anguloso & $\leq 0.17$ \\
\hline Anguloso & $0.17-0.25$ \\
Sub-angular & $0.25-0.35$ \\
Sub-arredondado & $0.35-0.49$ \\
Arredondado & $0.49-0.70$ \\
Muito arredondado & $\geq 0.70$ \\
\hline
\end{tabular}

Sendo assim, através do uso do PDI agregado a classificação proposta por (Powers, 1953) foi possível verificar que a maior parte dos grãos da lâmina analisada neste trabalho são subarredondados e arredondado, como pode ser observado na figura 10.

A fim de se ter uma análise mais detalhada em relação aos grãos presentes na lâmina e com o intuito de observar o comportamento dos grãos e seus respectivos parâmetros de forma, foram selecionados 4 grãos que foram analisados individualmente e comparados entre si. Esta análise pode ser visualizada na figura 11 , onde os grãos estão numerados de I a IV e são representados pelas cores azul, laranja, cinza e amarelo respectivamente.

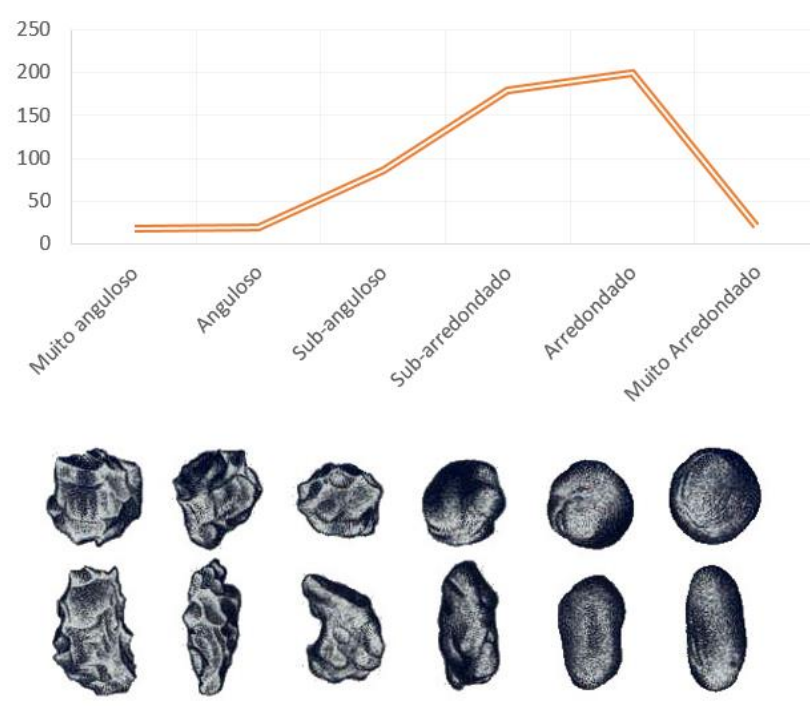

Figura 10. Gráfico da classificação de arredondamento proposto por (Powers, 1953) aplicada aos grãos da lâmina delgada do arenito Idaho, comparado com a ilustração de cada classe (Powers, 1953).

Os primeiros parâmetros analisados foram a angulosidade e circularidade. Os dois parâmetros apresentam relação com o transporte do sedimento, como já discutido. Logo, ao observar o gráfico comparativo entre estes dois parâmetros na figura 11 é possível perceber que os valores são praticamente iguais em cada grão com a exceção do grão IV, onde as linhas se desencontram. Outra informação relevante que pode ser observada ao analisar os histogramas é que os 4 grãos apresentam angulosidade acima de 0.5 e conforme a classificação de (Powers, 1953) discutida anteriormente, os grãos podem ser classificados como sub-arredondado (II, III e IV) e arrendondado (I). A circularidade para os grãos analisados apresentou valores bem variados com o mínimo de 0.36 para o grão IV e máximo de 0.76 para o grão I. Sendo que este último (grão I) apesar de apresentar irregularidade na sua forma, sua borda não é pontiaguda, fato que pode ser explicado com seu alto valor tanto de angulosidade quanto de circularidade. 

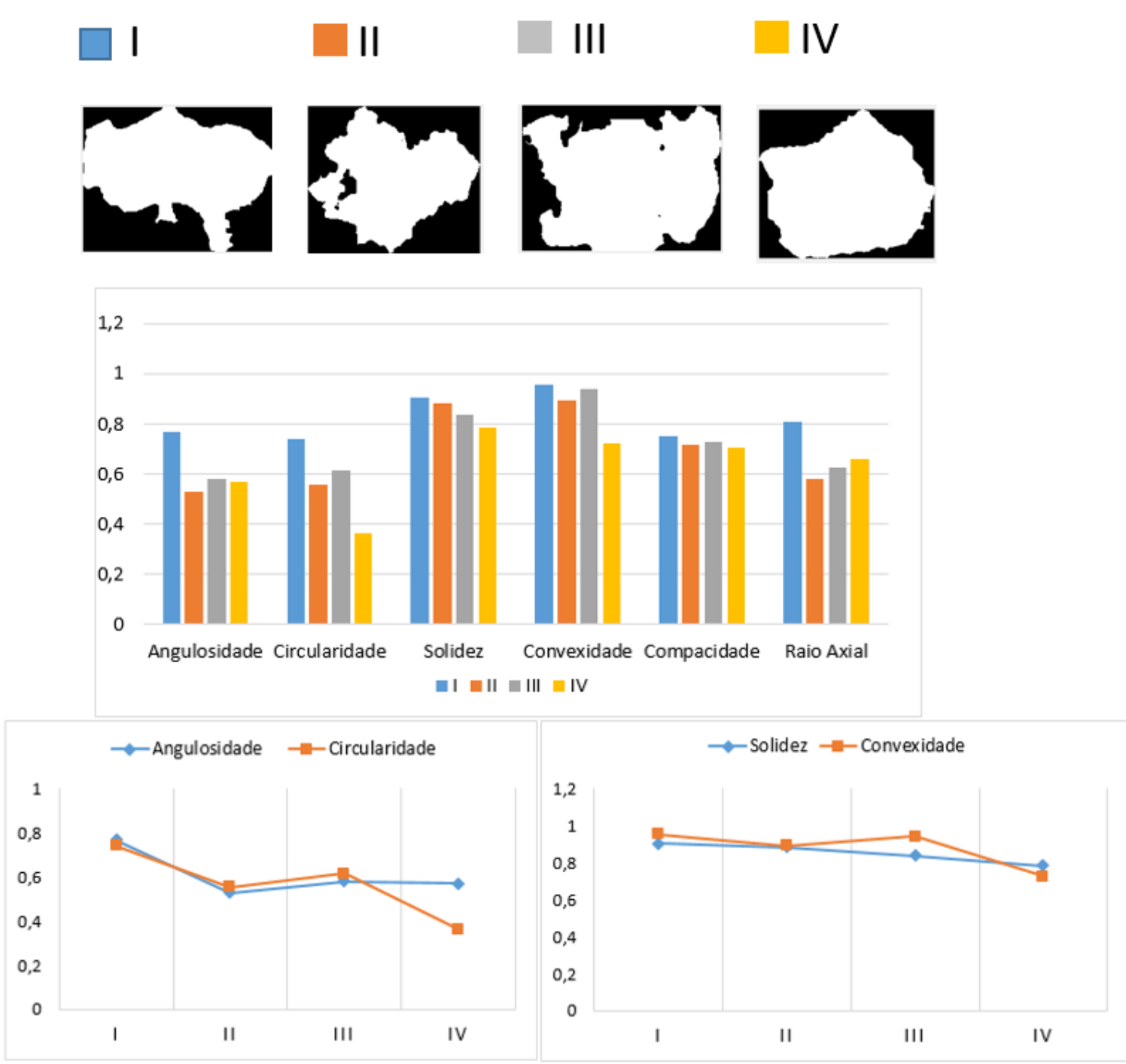

Figura 11. Histograma comparativo dos 6 fatores de forma discutido no trabalho em 4 grãos de areia da lâmina do arenito Idaho (Schön, 2011).

Para os parâmetros solidez e convexidade dos 4 grãos apresentados na figura 11 observase que os mesmos apresentam valores bem semelhantes com uma pequena diferença no grão III. Analisando o histograma da mesma figura é possível perceber que os valores destes parâmetros são altos, sendo valor máximo de solidez 0.90 e mínimo de 0.72. Já a convexidade apresenta valor máximo 0.95 e mínimo 0.78. A maior diferença encontrada entre convexidade e solidez é aproximadamente 0.1 entre os grãos analisados.

É esperado que a compacidade apresente pouca variação na maioria dos arenitos devido ao desgaste físico durante o transporte dos grãos. Isto é confirmado pelos valores analisados nos 4 grãos, que estão próximos de 0.7 e a variação entre o valor máximo e mínimo é 0.04 .
Conforme citado anteriormente partículas com forma simétrica em todos os eixos apresenta o raio axial igual a 1. Analisando a figura 11 o grão I é o único que apresenta a maior simetria entre os eixos com o valor de 0.8. Os demais grãos apresentam valores parecidos próximos a 0.6. A medida do Raio Axial é diretamente proporcional a angulosidade do grão, isso pode ser comprovado através da análise dos histogramas de ambas as medidas que apresentam formas bastante semelhantes.

Por fim, cabe ressaltar que ao comparar os 6 parâmetros de forma analisados neste trabalho, observou-se que existem alguns com relação alta e outras menores, entretanto, todos os parâmetros estão de alguma forma relacionados e são capazes de gerarem informações relevantes para o estudo petrográfico. 


\section{CONCLUSÕES E PREVISÕES FUTURAS}

O PDI se mostrou uma ferramenta eficaz para análise de tamanho e forma dos grãos presentes no Arenito Idaho.

Tamanho do grão, distribuição e forma do grão são fatores fundamentais e estes dados podem ser usados para tirar informações relevantes sobre uma rocha sedimentar. A caracterização do tamanho do grão via PDI mostrou um potencial para ser aplicado em grande escala para estudos desse tipo evitando o uso de técnicas laboratoriais que muitas das vezes são caras e lentas. $\mathrm{O}$ mesmo pode ser dito em relação ao estudo dos parâmetros de forma (circularidade, solidez, convexidade, compacidade, raio axial e angulosidade) apresentados neste trabalho, ou seja, a interpretação e comparação destes parâmetros podem ser avaliadas como um potencial para futuras aplicações.

Cabe destacar que existe uma falta de padronização na metodologia para caracterização quantitativa de formas de grãos. Foi constatado na bibliografia, ao longo do desenvolvimento deste trabalho, diversas formulações para cálculo do mesmo parâmetro e várias nomenclaturas diferentes para a mesma fórmula. Sendo assim, uma padronização da metodologia se faz necessário e poderá ajudar na difusão da utilização destes parâmetros para a caracterização de sedimentos.

\section{AGRADECIMENTOS}

Este trabalho é resultado colaboração entre CENPES e CBPF. Os autores gostariam de agradecer ao Dr. Rodrigo Surmas pela imagem de lâmina delgada utilizada neste trabalho.

\section{REFERÊNCIAS}

BUADES, A. A non-local algorithm for image denoising. Computer Vision and Pattern Recognition, v. 2, p. 60-65, 2005.

WENTWORTH, C.K. A scale of grade and class terms for clastic sediments. The Journal of Geology, v 30, n. 5, p. 377-392, 1922.

ALTUHAFI, F.; O'SUllivan, C.; CAVARRETTA, I. Analysis of Image-Based Method to Quantify the Size and Shape of Sand Particles. Journal of Geotechnical and Geoenvironmental engineering, p. 1290-1307, 2013.

ARTHUR, D. \& e VASSILVITSKII, S. k-means++: The Advantages of Careful Seeding. Proceedings of the eighteenth annual ACM-SIAM Symposium on Discrete Algorithms. Society for Industrial, 2007.

BELAID, L.J. \& MOUROU, W. Image segmentation: a watershed transformation algorithm. Image Anal Stereol, p. 93-102, 2009.

BOGGS JR., S. Petrology of Sedimentary Rocks. $2^{\mathrm{a}}$. Cambribge, 2009.

CHATTERJEE, S. Vision-based rock-type classification of limestone using multi-class support vector machine. Applied Intelligence v. 39, p.14-27, 2013.

COX, R.; LOPES, W.A.; JAHN, K.L. Quantitative roundness analysis of coastal boulder deposits. Marine Geology, v. 396, p. 114-141, 2018:

DELLINO, P. \& LA VOLPE, L. Image processing analysis in reconstructing fragmentation and transportation mechanisms of pyroclastic deposits. The case of Monte Pilato-Rocche Rosse eruptions, Lipari (Aeolian islands, Italy). Journal of Volcanology and Geothermal Research, v. 71, v 1, p. 13-29, 1996.

DIAS, J. M. A Análise sedimentar e o conhecimento dos sistemas marinhos: Uma Introdução à Oceanografia Geológica. Universidade do Algarve Faro. 84p. 2004.

DIPOVA, N. Determining the grain size distribution of granular soils using image analysis. Acta Geotechnlca Slovenica, v. 2017/1, p. 29-37, 2017.

DORNAIKA, F. \& ZHANG, H. Granulometry using mathematical morphological and motion. Conference on Machine Vision Applications, 51-54. 2000.

DUDA, R.O.; PETER, E.H.; STORK, D.G. Pattern
Classification, 2nd Edition. 2007.

FOLK, R. L. Petrology of Sedimentary Rocks. Austin - Texas: Hemphill Publishing Co, 1974.

FOLK, R.L. Petrology of sedimentary rocks. Hemphill Publishing Company, 1980.

FOLK, R.L. The distinction between grain size and mineral composition in sedimentary-rock nomenclature. Journal of Geology, v. 62, n. 4, p. 344-359, 1954.

FRIEDMAN, G.M. Determination of Sieve-Size Distribution from Thin-Section Data for Sedimentary. The Journal of Geology, v. 66, n. 4, p.394-416, 1958.

GIES, V. \& BERNARD, T.M. Statistical solution to watershed over-segmentation., ICIP'04. International Conference on Image Processing, 1863-1866. 2004.

GONZALEZ, R.C. \& WOODS, R.E. Processamento Digital de Imagens Digital. Edgard Blucher, 528 pp. 1998.

GONZALEZ, R.C. \& WOODS, R.E. Digital image processing. 779 pp. 2016.

HENTSCHEL, M.L. \& NEIL, W. Selection of descriptors for particle shape characterization. Particle and Particle Systems Characterization, 20 (1): 25-38. 2003.

ISHUTOV, S.; HASIUK, F.J.; GRAY, J.; HARDING, C. 3D printing sandstone porosity models. Interpretation, v. 3, n. 3, SX49-SX61, 2015

KARAKUS, D.; DELIORMANLI, A.H.; ONUR, A.H. Size and shape analysis of mineral particles using image processing. Journal of Ore Dressing, v. 12, p. 1-8, 2010.

KAUR, D. \& KAUR, Y. Various image segmentation techniques: a review. International Journal of Computer Science and Mobile Computing, v. 3, n. 5, p. 809-814, 2014.

KÖRBES, A. Análise do algoritmo da transformada whatershed. Tese (Mestrado Computação). Unicamp, 2010.

LIU, E. J.; CASHAMAN K.V.; RUST, A.C. Optimising shape analysis to quantify volcanic ash morphology. Geo Res J, p. 14-30, 2015.

MATHWORKS. https://www.mathworks.com/help/images/ref/ applycform.html. 2017.

MEYER, F. Un algorithme optimal pour la ligne de partage des eaux.,. Lyon, France: 8me congrès de reconnaissance des formes et intelligence artificielle, v. 2, p.847-8571991. 
POWERS, M.C. A new roundness scale for sedimentary particles. Journal of Sedimentary Petrology, v. 23, n. 2, p117119, 1953.

READING, H.G. Sedimentary environments processes, faceis and stratigraphy, v. 3 ed. Blackwell Publisinhing, 1996.

SCHÖN, J.H. Physical Properties of Rock- a Workbook. Handbook of Petroleum exploration, v. 8, 2011.

SERRA, J. Image Analysic and Mathematical Morphology. Academic Press, Inc. Orlando, FL, USA, 1983.

SOILLE, P. Morphological Image Analysis: Principles and Applications, Springer-Verlag, 1999, p. 170-171, 1999.

VARGA, G.; KOVÁCS, J.; SZALAI, Z.; CSABA, C. Granulometric characterization of paleosols in loess series by automated static image analysis. v. 370, p.1-14, Sedimentary Geology, 2018 .
ZINGG, T. Beitrag zur schotteranalysis: Sehwertz. Min. Pet. Mitt., v. 15, p. 39-140, 1935.

Submetido em 2 de agosto de 2018 Aceito em 3 de maio de 2019 